\title{
TENTOONSTELLING \\ HET TERRACOTTA LEGER VAN XI'AN; \\ SCHATTEN VAN DE EERSTE KEIZER VAN CHINA
}

Voor het eerst in Nederland, en exclusief voor het Drents Museum, zijn de originele wereldberoemde soldaten van het grafcomplex van Qin Shi Huangdi, de eerste keizer van China te zien. Deze levensgrote terracotta beelden worden omringd door ruim 200 grafgiften van goud, jade, brons en aardewerk uit de Qin- (221-206 v.Chr.) en Westelijke Han-dynastie (202 v.Chr. - 9 n.Chr.). Bezoekers van de tentoonstelling krijgen een impressie van de indrukwekkende inspanningen die zijn geleverd om de keizers te behagen tijdens hun dood en ontmoeten meer dan één terracotta leger.

Het landschap rondom de huidige stad Xi'an in de provincie Shaanxi wordt gekarakteriseerd door de vele oude grafheuvels die getuigen van de band met de keizerrijken uit het verre verleden: ze markeren de dodenrijken van de oude keizers. Vele reislustigen die tegenwoordig afreizen naar Xi'an om het terracotta leger van de Eerste Keizer van China te bewonderen hebben echter niet het besef dat dit leger deel uitmaakt van een groter geheel. Het rituele landschap dat een samensmelting was van het natuurlijke landschap met de grafarchitectuur is namelijk boven de grond verdwenen. Ondergronds bevinden zich vele offerkuilen met voorwerpen die al eeuwen de ziel van de keizers dienen. De confucianistische filosoof Xunzi schreef in de derde eeuw voor Christus over de dodencultus dat de dode met een volledige representatie van zijn leven naar zijn laatste rustplaats moest worden begeleid. Archeologisch onderzoek naar de grafcomplexen van de eerste keizers van China toont dat de graven hun wereldrijk weerspiegelen. Een mausoleum was een paleis voor de eeuwigheid, dat ingericht diende te zijn met vertrekken en voorwerpen die deze functie waardig zijn en praktisch mogelijk maken. Men ging ervan uit dat de geest van de dode in de tombe aanwezig was en dat deze voedsel en andere bezittingen nodig had voor het dagelijkse leven in het hiernamaals. Dankzij de offers van voorwerpen kon de overledene in het hiernamaals blijven genieten van de vele geneugten waaraan hij tijdens zijn leven gewend was geraakt.

De grafgiften zijn in te delen in drie verschillende categorieën voorwerpen. Ten eerste zijn er rituele voorwerpen teruggevonden in de graven die voorheen in tempels gebruikt zijn. Een jade $b i$-schijf is een dergelijk ritueel voorwerp dat gebruikt werd bij ceremonies ter verering van de keizer als zoon van de hemel. Ook hebben de doden alledaagse gebruiksvoorwerpen meegekregen, zoals munten of spiegels. Hierbij speelde symboliek een belangrijke rol; een spiegel weerde kwade geesten af. Daarnaast zijn spirituele voorwerpen meegegeven, voorwerpen die uitsluitend voor het graf zijn gemaakt. Deze voorwerpen hebben het uiterlijk van functionele voorwerpen maar de oorspronkelijke praktische functie hebben ze bewust verloren. Zo js: een bronzen wijnvat in miniatuur nagemaakt in aardewerk. Deze spiriturele access 

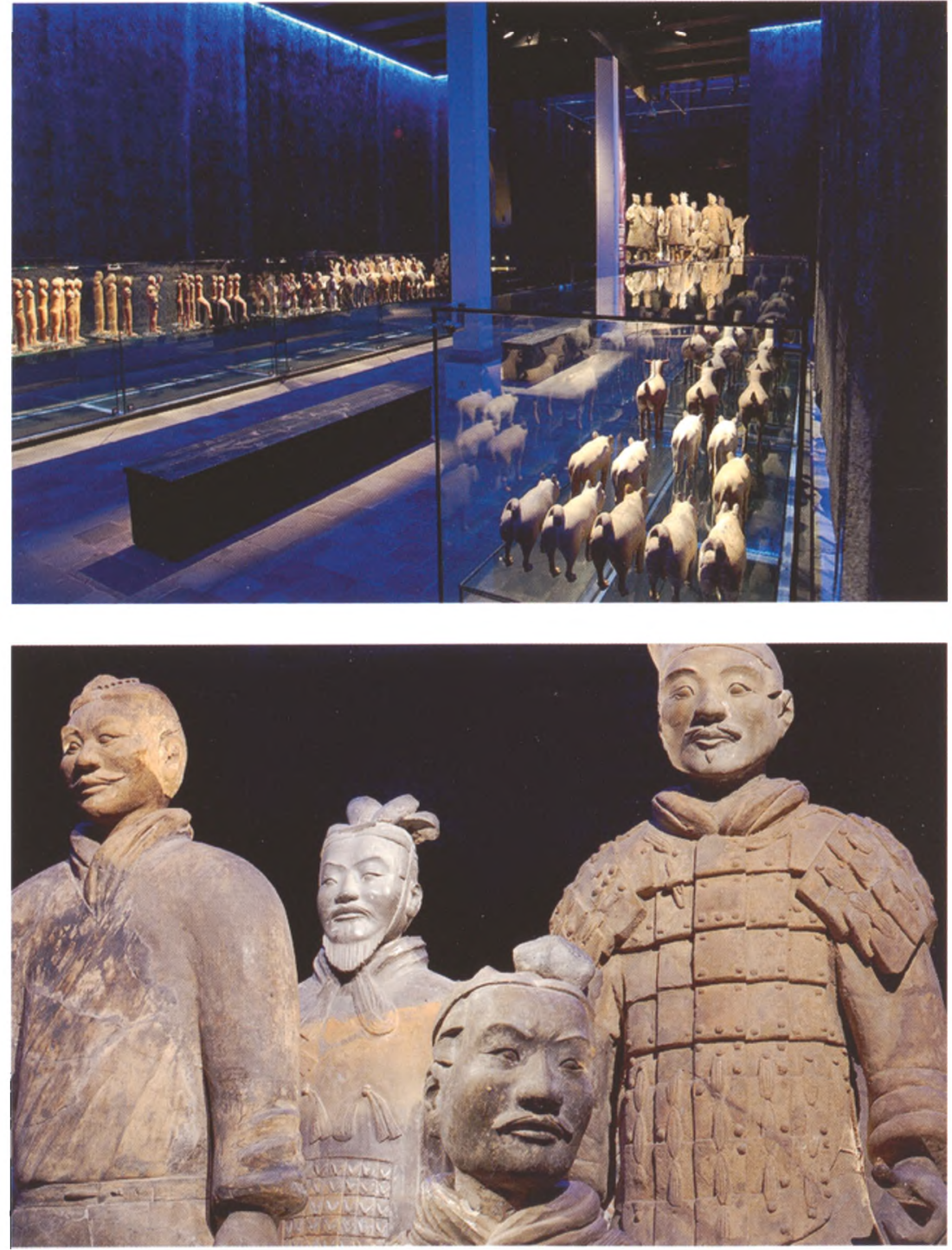

voorwerpen stonden symbool voor de activiteiten die de persoon tijdens zijn leven ook uitvoerde en dus ook in het hiernamaals wilde uitvoeren. Niet alleen de vorm van de voorwerpen maar ook het gebruikte materiaal had een diepere betekenis. Jade zou een balsemende werking hebben, goud is duurzaam en stond daarom symbool voor de eeuwigheid.

De climax van het bezoek aan de tentoonstelling is de ontmoeting met de terracotta soldaten en de hofhouding van de eerste keizers van China. Deze 14 levensgrote beelden uit het grafcomplex van Qin Shi Huangdi en bijna honderd miniatuurbeelden van de keizers en adel van de Han-dynastie zijn eveneens grafgiften die de overleden keizers dienden. Het levensgrote terracotta leger is de beroemdste grafgift van de Eerste Keizer. Op ongeveer 2 kilometer afstand van zijn grafheuvel staan in drie enorme kuilen de verschillende eenheden van dit leger uit de Qin-dynastie opgesteld. Er zouden zeven à

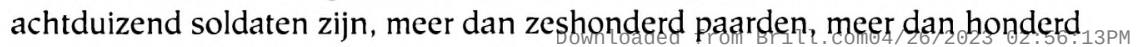
strijdwagens en duizenden bronzen wapens. In dit terracotta leger kunrien weess 
zeven verschillende rangen onderscheiden, ieder herkenbaar aan zijn uniform. Iedere soldaat heeft een eigen postuur, van lang en iel tot fors met een klein buikje. Elk gezicht heeft persoonlijke details: de wenkbrauwen zijn steeds verschillend, de neuzen, oren en lippen net weer iets anders bij de ene of andere soldaat. De oorspronkelijke beschildering van de beelden moet nog meer bijgedragen hebben aan een levensecht uiterlijk van deze soldaten. Door de tand des tijds, het indringende vocht en veranderde klimaatsomstandigheden zijn deze kleuren helaas op veel beelden bijna helemaal uitgewist.

Qin Shi Huangdi is niet de eerste die terracotta beelden mee heeft genomen in zijn graf en is zeker niet de laatste geweest. Tijdens de Han-dynastie bereikt het enthousiasme van de keizers voor het bouwen van hun tombes een hoogtepunt. De overledenen werden gezelschap gehouden door terracotta dienaren, muzikanten, minstrelen en dames. Daarnaast werden ze vaak beschermd door terracotta legers. Het opvallendste kenmerk van deze terracotta beelden is de afmeting: het zijn allemaal miniaturen. Sommige zijn uitsluitend gemaakt van aardewerk, andere hebben houten onderdelen. Deze houten onderdelen zijn vergaan. Ook de zijden stoffen die gebruikt zijn voor de kleding van de exclusieve beelden voor de keizerlijke familie, vinden we niet meer terug. De blote soldaten van keizer Jingdi zijn echter, zelfs ontdaan van hun kleding, nog van een grote schoonheid. De aanwezigheid van grafgiften als de kleine terracotta legers van de keizers en de adel kan een grote verrassing worden genoemd na het levensgrote terracotta leger van de Eerste Keizer maar ze zijn het logische gevolg van de ontwikkelingen in grafrituelen in de eerste eeuwen voor Christus in dit gebied. Klein, maar zo gracieus dat het adembenemend is, beschermen ook deze terracotta legers hun heer en meester.

- De tentoonstelling 'Het Terracotta Leger van Xi'an; schatten van de eerste keizers van China' is onderdeel van het 'Go China! Assen-Groningen'-project, een samenwerking tussen het Drents Museum en het Groninger Museum, waarbij in totaal vijf tentoonstellingen worden gepresenteerd.

Op de site www.gochina-assen-groningen. $\mathrm{nl}$ vindt $\mathrm{u}$ ook meer informatie. 